Systematic literature review

\title{
Behavioral comparisons in Autism Spectrum Disorder and Developmental Coordination Disorder: A systematic literature review
}

\author{
Priscila Caçola ${ }^{\mathrm{a}, *}$, Haylie L. Miller ${ }^{\mathrm{b}}$, Peace Ossom Williamson ${ }^{\mathrm{c}}$ \\ a Department of Kinesiology, University of Texas at Arlington, United States \\ ${ }^{\mathrm{b}}$ Department of Physical Therapy, University of North Texas Health Science Center, United States \\ ${ }^{\mathrm{c}}$ Library, University of Texas at Arlington, United States
}

\section{A R T I C L E I N F O}

\section{Article history:}

Received 1 July 2016

Received in revised form 8 March 2017

Accepted 10 March 2017

Number of reviews: 3 .

Available online 25 March 2017

\section{Keywords:}

Autism Spectrum Disorder

Developmental Coordination Disorder

Behaviors

Co-morbidities

Co-occurrence

Motor skills

Systematic literature review

\begin{abstract}
A B S T R A C T
Background: Autism Spectrum Disorder (ASD) and Developmental Coordination Disorder (DCD) are developmental disorders that, since the DSM-5, can be diagnosed as co-occurring conditions. While some recent studies suggest that ASD and DCD have similar traits, others show clear behavioral distinctions between the two conditions. By gathering all studies that included (1) an ASD group and a DCD group, (2) an ASD + DCD group and a DCD group, or (3) ASD, ASD + DCD, and DCD groups, we aimed to identify similarities and differences in behaviors between the two disorders.

Method: We used a systematic search of PubMed (1946 -), Scopus (1970 -), PsycINFO (via EBSCO, 1600 -), CINAHL (via EBSCO, 1937 -), SportDiscus (via EBSCO, 1985 -), and WorldCat (via FirstSearch) in addition to reference list and author name searching PubMed, Scopus, PsycINFO, CINAHL, SportDiscus, and WorldCat to identify original studies that met the following criteria: (1) an ASD group and a DCD group, (2) an ASD + DCD group and a DCD group, or (3) ASD, ASD + DCD, and DCD groups.

Results: From the 1598 articles screened, 11 were included in the qualitative analysis. The articles included reported more differences than similarities in individuals with ASD and DCD, with clear distinctions for working memory ability, gestural performance, grip selection, and cortical thickness. Only two studies reported similarities in face processing abilities and perceived competence, and the interventional studies showed group similarities in behavior improvement, such as intelligence and attention.

Conclusions: Based on the articles reviewed, we conclude that while DCD and ASD share some behavioral symptoms, the symptom profiles of each disorder are unique and separable. We recommend that the evaluation of potential DCD in individuals with ASD be performed systematically and thoroughly, so as to distinguish this co-occurring condition from sensorimotor symptoms associated with ASD.
\end{abstract}

(c) 2017 Elsevier Ltd. All rights reserved.

\section{Contents}

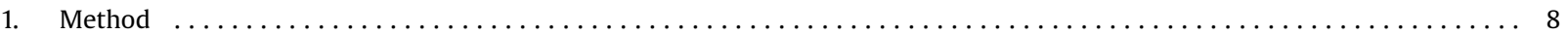

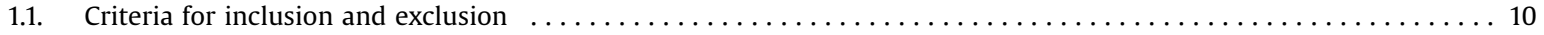

\footnotetext{
* Corresponding author at: Department of Kinesiology, University of Texas at Arlington, Arlington, TX 76019, United States.

E-mail address: cacola@uta.edu (P. Caçola).
} 


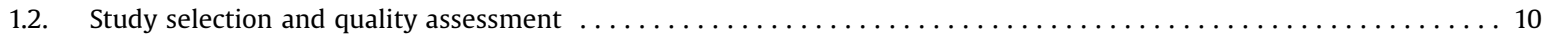

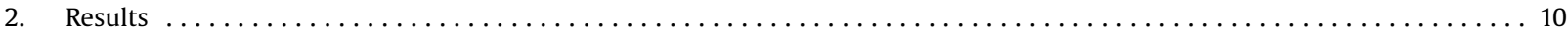

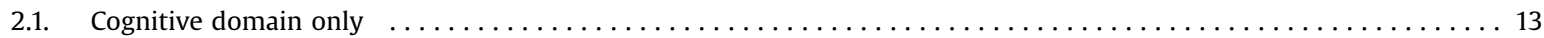

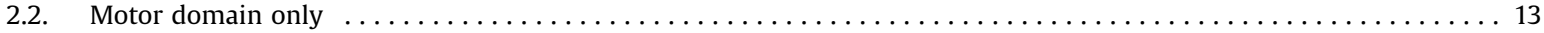

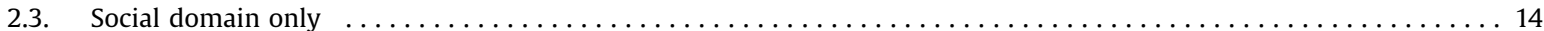

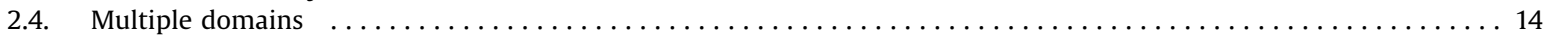

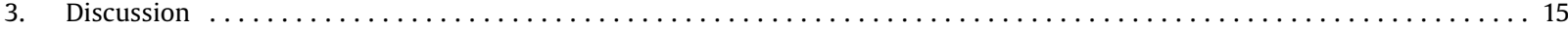

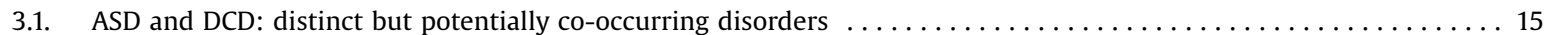

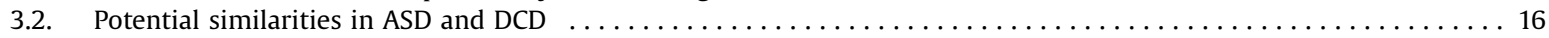

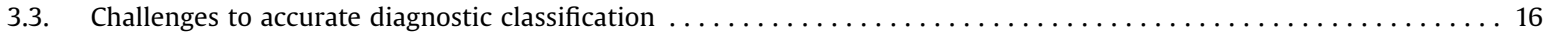

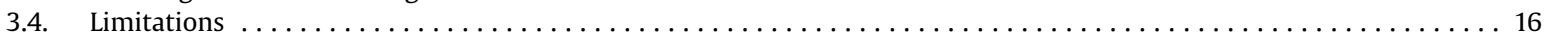

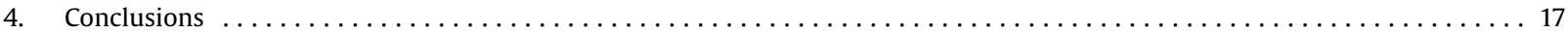

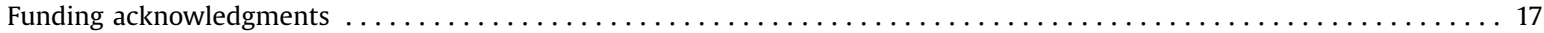

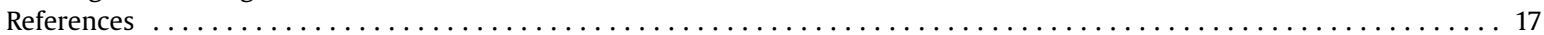

Autism Spectrum Disorder (ASD) and Developmental Coordination Disorder (DCD) are developmental disorders with distinct definitions and diagnostic criteria. ASD is currently diagnosed based on symptoms in two core domains: difficulty with social interaction/communication, and restricted interests and repetitive behaviors. DCD, on the other hand, is characterized by significant difficulty performing motor skills at an age-appropriate level. Individuals with DCD experience substantial impact of these difficulties on everyday tasks as well as in social relationships (Leonard \& Hill, 2014). Due to recent changes in the Diagnostic and Static Manual for Mental Disorders-Fifth Edition (DSM-5) in 2013, these two conditions can be diagnosed as co-occurring in certain individuals (e.g., children with ASD with significant difficulties in motor skills can also be diagnosed with DCD). However, questions remain on behavioral similarities and differences in profiles of individuals that have ASD, individuals that have DCD, and individuals diagnosed with both conditions, in motor behavior as well as in other domains. Therefore, this review aimed to investigate similarities and differences of behaviors in children diagnosed with DCD, ASD, or both at the same time. This examination has important clinical implications, given the increasing attention paid to sensorimotor features of ASD (e.g., Donnellan, Hill, \& Leary, 2013; Fournier et al., 2010; Whyatt \& Craig, 2013). It is crucial to determine which behavioral and motor challenges are part of the core symptom profile of ASD, and whether they are fundamentally different in a sub-set of individuals with ASD and co-occurring DCD (hereafter abbreviated as ASD + DCD).

DCD is characterized by difficulties in performing accurate and fast gross- and fine-motor skills, including problems with coordination and balance. The movements of children with DCD frequently lead to performance difficulties in activities of daily living and physical games that typically-developing (TD) children perform easily. Many researchers use the terms "dyspraxia" and DCD interchangeably. However, some have argued that dyspraxia is a condition specifically impacting the ability to plan unfamiliar motor tasks (Bundy, Lane, \& Murray, 2002), or to perform skilled gestures (Dziuk et al., 2007). For the purpose of this discussion, we consider these two conditions similar in their clinical characteristics, as indicated by the European Academy of Childhood Disability (EACD) guidelines (Blank, Smits-Engelslman, Polatajko, \& Wilson, 2012).

DCD has been described as a "hidden problem" (Gibbs, Appleton, \& Appleton, 2007), with an estimated prevalence as high as $10 \%$ in school-aged children. In general, estimates of $2 \%$ to $7 \%$ are more likely (APA, 2013), implying that most school classes have at least one affected child. The diagnostic process involves assessing motor skills, evaluating whether these skills affect daily living, determining whether there was an early onset of motor delays, and ensuring that the disturbance was not due to a general medical and/or neurological condition. Prior to the changes in the DSM-5, the diagnostic criteria for DCD included ruling out the presence of a co-occurring Pervasive Developmental Disorder (PDD): a category that, at the time, included Autistic Disorder (AD), Asperger's Syndrome (AS), Rett's Syndrome, and PDD-Not Otherwise Specified (PDD-NOS). The most recent revision of the DSM eliminated this rule, making it possible for an individual to be diagnosed with cooccurring ASD + DCD.

In DSM-5, a single diagnostic code-Autism Spectrum Disorder (ASD)-replaces the earlier diagnoses of AD, AS, and PDDNOS. ASD is a broad term used for a clinical population characterized by complex and often heterogeneous patterns of biological and behavioral symptoms, with shared features in the domains of communication and social interaction, and restricted interests and repetitive behaviors (APA, 2013). ASD affects a lower proportion of children than DCD, with prevalence estimates at 1 in 68 children (Christensen et al., 2016). In addition to the behaviors described above, motor impairments are a common symptom of ASD, and have been observed from the earliest descriptions of the disorder (Kanner, 1943). Ozonoff and colleagues (2008) and others have suggested that motor disturbances appear to be among the first manifestations of developmental abnormalities in ASD, and could serve as biomarkers of this condition in the first years of life before other core symptoms (i.e., social communication, restricted interests) can be reliably measured. Fournier et al. (2010) concluded after a systematic literature review and meta-analysis that motor coordination deficits are pervasive across the range of ASD-related diagnoses, and can be considered a cardinal feature of ASD. In general, several researchers suggest that when compared to typically-developing (TD) individuals, individuals with ASD also have significant motor praxis and coordination impairments, although they may not carry a formal diagnosis of dyspraxia or DCD (Downey \& Rapport, 2012; Dziuk et al., 2007). 
Neither gross- nor fine-motor impairments are an essential or defining characteristic of ASD in the current diagnostic framework (Green et al., 2002), despite the fact that they are recognized as a common feature. As a result, previous diagnostic criteria did not provide a means of differentiating between individuals with ASD who had motor problems and those who did not (Founder-Hughes \& Prior, 2014). When evaluating potential DCD, Missiuna and Magalhães (2015) caution that clinicians must carefully evaluate criterion D of the DSM-5. That is, they must determine whether the motor deficits observed could be better explained by other disabilities or neurological condition, such as ASD. The authors explain that while this is open to interpretation, physical and occupational therapists will often be in the best position to determine whether (1) the motor challenges of a child with ASD are better explained by ASD, or (2) the motor difficulties reflect the co-occurrence of DCD ( $p$. 94). However, little is known about the differences and similarities of behaviors that individuals with ASD and DCD demonstrate, and physical and occupational therapists receive limited training in differentiating between these two conditions.

Therefore, the aim of this systematic literature review (SLR) was to identify: (a) what types of behaviors (variables) have been investigated in ASD and DCD to determine similarities or differences between the conditions, and (b) whether any of the studies that met our criteria had a group of ASD + DCD or explored the possibility of co-occurrence between ASD and DCD.

\section{Method}

In order to identify separable and overlapping features of these two disorders, we conducted a SLR gathering all studies that investigated behavioral profiles of individuals diagnosed with ASD, DCD, and ASD + DCD (if included) and their derivatives. Because of the high rate of co-occurrence among neurodevelopmental conditions (Jongmans et al., 2003; Kaplan et al., 2001; Simonoff et al., 2008), we included papers that used groups with other conditions as well as TD individuals. The SLR process involves gathering all existing knowledge using a thorough and methodical approach and summarizing the best available research on a specific topic or question, in order to provide a repeatable method that reduces reporting bias.

This review follows the Preferred Reporting Items for Systematic Reviews and Meta-Analysis (PRISMA) standards described by Moher, Liberati, Tetzlaff, and Altman (2009). A systematic search of all full-length studies was performed by an information specialist (POW) on November 9, 2015 (the unregistered protocol is available by request). The databases searched were PubMed (1946 -), Scopus (1970 -), PsycINFO (via EBSCO, 1600 -), CINAHL (via EBSCO, 1937 -), SportDiscus (via EBSCO, 1985 -), and WorldCat (via FirstSearch). The search terms and relevant subject headings for DCD were grouped together using the Boolean operator OR; search terms and subject headings for ASD were also grouped using OR. Both groups were contained within parentheses and combined with the AND Boolean operator to create the final search. In PubMed and Scopus, to exclude research on animals, the following string was added to the search with the NOT Boolean operator: (animal* OR rat OR rats OR mouse OR mice). Table 1 shows the search keywords by group.

Table 1

Search keywords by group.

\begin{tabular}{|c|c|c|c|}
\hline \multicolumn{2}{|l|}{ DCD } & \multicolumn{2}{|l|}{ ASD } \\
\hline Subject Headings $^{a}$ & Keywords $^{\mathrm{b}}$ & Subject Headings ${ }^{\mathrm{a}}$ & Keywords $^{\mathrm{b}}$ \\
\hline $\begin{array}{l}\text { “Motor Skills Disorders" } \\
\text { “Neurogenerative Diseases" } \\
\text { “Agraphia” } \\
\text { “Dyspraxia” } \\
\text { "Psychomotor Disorders" } \\
\text { “Apraxia” } \\
\text { “Movement Disorders" }\end{array}$ & $\begin{array}{l}\text { "Developmental coordination disorder" } \\
\text { DCD } \\
\text { "Developmental co-ordination disorder" } \\
\text { Dyspraxia } \\
\text { Dyspraxic } \\
\text { Maladroitness } \\
\text { "Clumsy child" } \\
\text { Dyscoordination } \\
\text { Dys-coordination } \\
\text { Dysgraphia } \\
\text { "Minimal brain dysfunction" } \\
\text { "Sensorimotor difficulties" } \\
\text { "Sensorimotor dysfunction" } \\
\text { "Sensory integrative dysfunction" } \\
\text { "Psychomotor disorder" } \\
\text { "Perceptual motor dysfunction" } \\
\text { "Minimal cerebral dysfunction" } \\
\text { "Developmental right hemisphere syndrome" } \\
\text { "Minimal brain dysfunction" } \\
\text { "Minor neurological dysfunction" }\end{array}$ & $\begin{array}{l}\text { "Autistic Disorder" } \\
\text { "Autism" } \\
\text { "Autistic Spectrum Disorders" } \\
\text { Autistic Thinking }\end{array}$ & $\begin{array}{l}\text { Autistic } \\
\text { Autism } \\
\text { Asperger's } \\
\text { Aspergers } \\
\text { ASD } \\
\text { "Pervasive developmental disorder" } \\
\text { "Childhood disintegrative disorder" }\end{array}$ \\
\hline
\end{tabular}

\footnotetext{
a Subject headings include MeSH in PubMed and CINAHL, SPORTDiscus, and PsycINFO headings.

b Truncation (e.g., autis*) was used for keywords in Scopus, PyscINFO, CINAHL, and SPORTDiscus.
} 
There were no publication date restrictions. Filters were used to limit our search to English-language studies of humans. To update the systematic review, the searches were repeated in each database on July 9, 2016 and November 3, 2016 and results were added to the aforementioned RefWorks account for the systematic review. Fig. 1 illustrates the search process from identification and inclusion of articles. Authors' names and reference lists from the 120 studies remaining after primary screening were also used to find additional studies. The authors' names of these 120 studies were searched, including a review of faculty profile pages and author pages in WorldCat to identify any additional studies. One study was sent to the

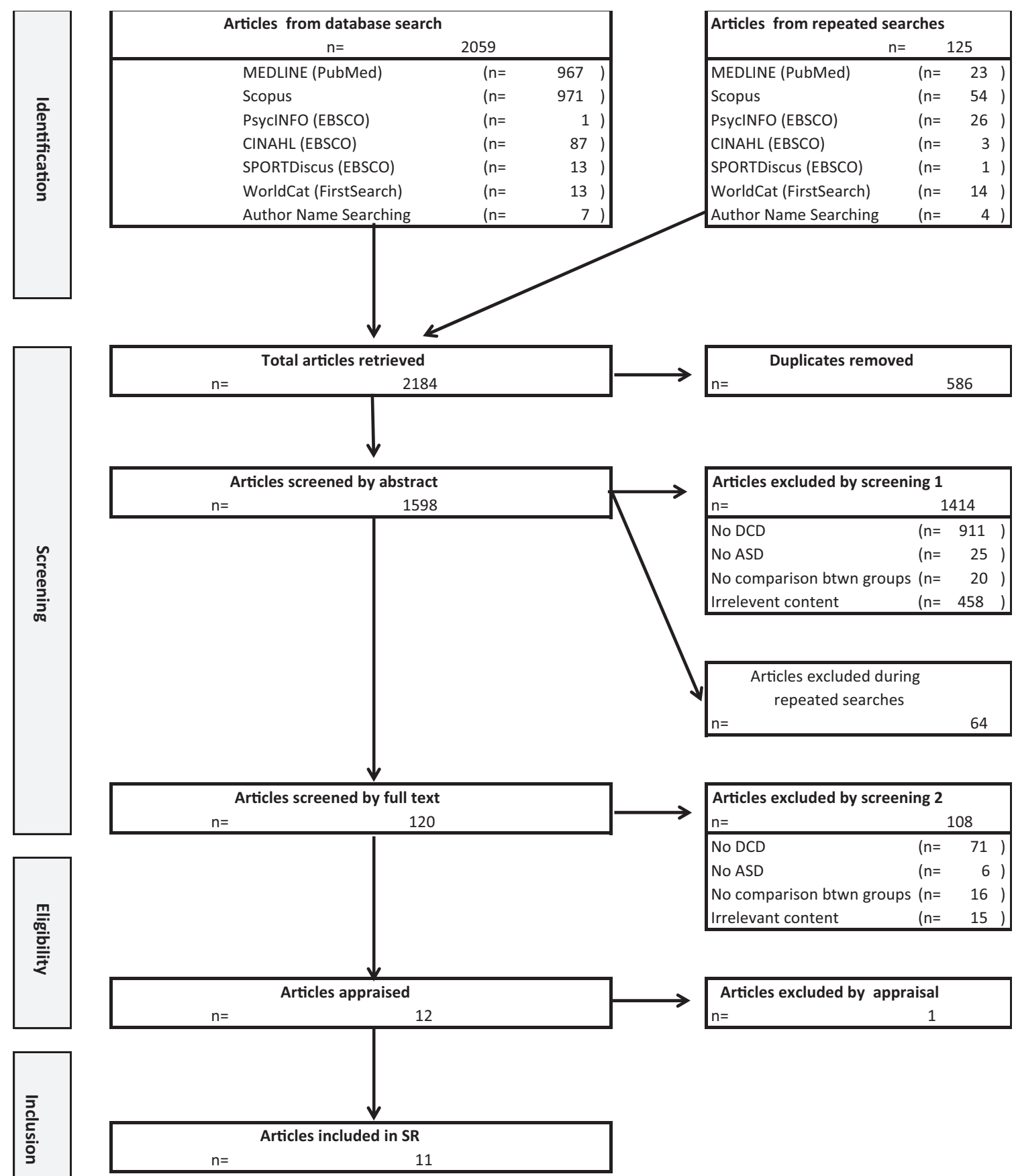

Fig. 1. PRISMA Flowchart. 
authors. A total of 1598 articles were retrieved from database, author, and reference list searching. The metadata of the studies retrieved were imported and encoded in the RefWorks 2.0 web-based bibliographic program.

\subsection{Criteria for inclusion and exclusion}

We limited our review of the literature to studies that included at least two groups of individuals: (1) an ASD group and a DCD group, (2) an ASD + DCD group and a DCD group, or (3) ASD, ASD + DCD, and DCD groups. Some studies included additional groups, but provided that they met the previous criteria, they were included. Our goal was to compare the profile of these individuals as determined by each study. We included all relevant DSM-IV diagnostic categories (AS, AD, PDD-NOS). All outcome measures typically used in the assessment of behavioral symptom severity in DCD and ASD (e.g., fine-motor, gross-motor, and psychosocial variables) were included. Studies that did not include participants with ASD and participants with DCD were excluded, and review articles were excluded.

\subsection{Study selection and quality assessment}

Through primary screening of the titles and abstracts of the retrieved studies, 120 studies remained. During secondary screening, two independent reviewers (PC and HM) evaluated the abstracts and full text of these 120 studies according to the inclusion and exclusion criteria. At the conclusion of secondary screening, 12 studies met criteria for inclusion. During this analysis, the reviewers agreed that one article should be removed from the final inclusion (Van Waelvelde et al., 2010). While the study aimed to investigate the stability of motor problems in a sample of children with or at risk for ASD, ADHD, and/or $\mathrm{DCD}$, none of the participants were given a DCD diagnosis (a DCD diagnosis is not typically given before 6 years of age). Therefore, for this article, it was not possible to determine the stability of motor problems in the ASD and DCD groups.

Because we were not able to find a gold-standard tool that would give us a good quality assessment of the articles selected for this SLR, we adopted criteria based on the PRISMA standards that reflected the quality of the studies meeting the search criteria. These criteria included appropriate selection and description of participants, use of appropriate outcome measures, appropriate statistical analysis, consideration of confounding factors, and a discussion of implications and limitations of the findings. This resulted in a list of seven questions to be answered with a "yes" or "no" that were used for each one of the articles selected, showed in Table 2. Articles that scored a "no" in more in four or more of the questions were classified as 'poor quality', articles with a "no" for 3 questions were classified as 'average quality', and articles with two or less "no" answers were classified as 'high quality'.

\section{Results}

Upon final screening, a total of eleven articles reporting data spanning cognitive, motor, social, and multiple domains were acceptable for the SLR (full description of studies provided in Table 3), all of which were published in the last 10 years. These studies reported data from individuals between 3 and 20 years of age. Among these individuals, 295 were identified as DCD, 182 were diagnosed with ASD, and 12 were diagnosed with ASD + DCD. Six studies compared only ASD and DCD, four of which also included a TD group. As expected, only two recent studies involved a group of individuals diagnosed with ASD + DCD (Caeyenberghs et al., 2016; Foulder-Hughes \& Prior, 2014), and one study discussed the possibility that DCD may be part of the autism spectrum (Wisdom et al., 2007). Five studies explored other groups in addition to DCD and ASD (Specific Language Impairment [SLI], Attention Deficit Hyperactivity Disorder [ADHD], Down Syndrome [DS], Intellectual Disability [ID], Cerebral Palsy [CP], Receptive-Expressive Language Disorder [RELD], and typical development [TD]).

The results of the quality assessment are presented in Table 3. Seven studies were classified as high quality, one was classified as average quality, and three were classified as poor quality. Most of the poor quality studies reflected a selection

Table 2

Quality assessment.

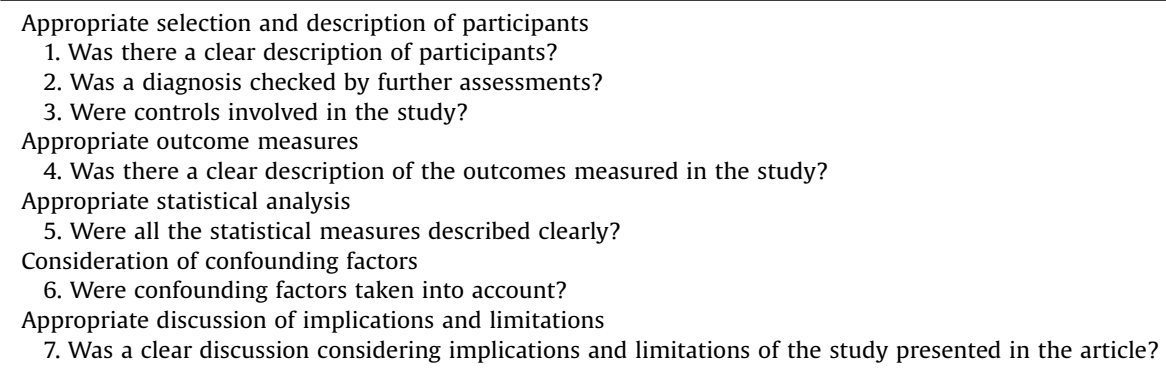


Table 3

Description of studies included.

\begin{tabular}{|c|c|c|c|c|c|c|c|c|}
\hline Study & Design & Variable(s) & Disorders (n) & $\begin{array}{l}\text { Group } \\
\text { matching }\end{array}$ & $\begin{array}{l}\text { Age } \\
\text { (years) }\end{array}$ & $\begin{array}{l}\text { Summary of } \\
\text { findings }\end{array}$ & Observations & Quality \\
\hline $\begin{array}{l}\text { Alloway, } \\
\text { Rajendran, } \\
\text { and } \\
\text { Archibald } \\
\text { (2009) }\end{array}$ & $\begin{array}{l}\text { Cross- } \\
\text { sectional }\end{array}$ & $\begin{array}{l}\text { Working memory } \\
\text { (Automated } \\
\text { Working Memory } \\
\text { Assessment) }\end{array}$ & $\begin{array}{l}\text { SLI (15) } \\
\operatorname{DCD}(55) \\
\text { ADHD (83) } \\
\text { AS (10) }\end{array}$ & $\begin{array}{l}\text { Similar age } \\
\text { Children in } \\
\text { SLI group did } \\
\text { not show } \\
\text { motor } \\
\text { difficulties }\end{array}$ & $8-11$ & $\begin{array}{l}\text { DCD: noticeable } \\
\text { visuospatial deficits } \\
\text { AS: only showed } \\
\text { poor performance } \\
\text { on verbal short- } \\
\text { term memory }\end{array}$ & $\begin{array}{l}\text { * Autism group had } \\
\text { Aspergers }\end{array}$ & High \\
\hline $\begin{array}{l}\text { Cosper et al. } \\
\text { (2009) }\end{array}$ & Interventional & $\begin{array}{l}\text { Attention } \\
\text { (Vigilance task, } \\
\text { Model III-R) } \\
\text { Motor skills } \\
\text { (Bruininks- } \\
\text { Oseretsky Test of } \\
\text { Motor Proficiency- } \\
\text { Short } \\
\text { Form) }\end{array}$ & $\begin{array}{l}\text { ADHD + PDD } \\
(2) \\
\text { ADHD + DCD } \\
(10)\end{array}$ & Similar age & $6-13$ & $\begin{array}{l}\text { All children made } \\
\text { significant } \\
\text { improvements in } \\
\text { complex visual } \\
\text { choice reaction time } \\
\text { and visuomotor } \\
\text { control after the } \\
\text { training }\end{array}$ & $\begin{array}{l}\text { * Both groups had } \\
\text { ADHD combined with } \\
\text { another disorder, } \\
\text { Autism was } \\
\text { considered "PDD", no } \\
\text { comparison between } \\
\text { groups }\end{array}$ & Low \\
\hline $\begin{array}{l}\text { Dewey, } \\
\text { Cantell, and } \\
\text { Crawford } \\
\text { (2007) }\end{array}$ & $\begin{array}{l}\text { Cross- } \\
\text { sectional } \\
\text { control group }\end{array}$ & $\begin{array}{l}\text { Motor skills } \\
\text { (Bruininks- } \\
\text { Oseretsky Test of } \\
\text { Motor Proficiency- } \\
\text { Short } \\
\text { Form) } \\
\text { Gestural skills } \\
\text { (Gestures Test }^{\mathrm{a}}{ }^{\text {) }}\end{array}$ & $\begin{array}{l}\text { ASD (49) } \\
\text { DCD + ADHD } \\
(38) \\
\text { ADHD (27) } \\
\text { DCD (46) } \\
\text { TD (78) }\end{array}$ & $\begin{array}{l}\text { Similar age } \\
\text { All groups } \\
\text { obtained IQ } \\
>70 \text { (except } \\
\text { for } 5 \text { children } \\
\text { in ASD group) } \\
\text { All groups } \\
\text { were tested } \\
\text { for ADHD } \\
\text { Most children } \\
\text { with ASD } \\
\text { scored low on } \\
\text { motor } \\
\text { functioning, } \\
\text { all DCD did, } \\
\text { and all TD } \\
\text { obtained high } \\
\text { scores }\end{array}$ & $5-18$ & $\begin{array}{l}\text { Children with ASD, } \\
\text { DCD, and } \\
\text { DCD + ADHD were } \\
\text { significantly } \\
\text { impaired on motor } \\
\text { coordination skills } \\
\text { Only ASD showed a } \\
\text { generalized } \\
\text { impairment in } \\
\text { gestural } \\
\text { performance }\end{array}$ & $\begin{array}{l}{ }^{*} \text { ASD group had PDD } \\
\text { and AS }\end{array}$ & High \\
\hline $\begin{array}{l}\text { Foulder- } \\
\text { Hughes, and } \\
\text { Prior (2014) }\end{array}$ & Qualitative & $\begin{array}{l}\text { Perceptions about } \\
\text { transition } \\
\text { (Interviews) }\end{array}$ & $\begin{array}{l}\text { DCD + ASD } \\
(4) \\
\text { DCD (1) } \\
\text { ASD (1) }\end{array}$ & Similar age & $10-11$ & $\begin{array}{l}\text { Children with DCD } \\
\text { and/or ASD have } \\
\text { anxiety related to } \\
\text { Physical Education } \\
\text { when transitioning } \\
\text { schools }\end{array}$ & * Qualitative study & Average \\
\hline $\begin{array}{l}\text { Kozulin et al. } \\
\text { (2010) }\end{array}$ & Interventional & $\begin{array}{l}\text { Cognitive } \\
\text { functioning } \\
\text { (Wechsler } \\
\text { Intelligence Scale } \\
\text { for Children } \\
\text { Revised, Raven } \\
\text { Coloured } \\
\text { Matrices) }\end{array}$ & $\begin{array}{l}\text { DS (51) } \\
\text { Genetic } \\
\text { Intellectual } \\
\text { disorders } \\
(12) \\
\text { Non-genetic } \\
\text { Intellectual } \\
\text { disorders } \\
(39) \\
\text { ASD (11) } \\
\text { CP (13) } \\
\text { DCD (45) } \\
\text { ADHD (2) } \\
\text { Other (15) }\end{array}$ & Similar age & $\begin{array}{l}5-7 \\
\text { (mental } \\
\text { age) }\end{array}$ & $\begin{array}{l}\text { IE-basic is a valid } \\
\text { program to enhance } \\
\text { general } \\
\text { cognitive } \\
\text { functioning in } \\
\text { children with } \\
\text { learning disabilities } \\
\text { and a mild to } \\
\text { moderate } \\
\text { intellectual } \\
\text { impairment }\end{array}$ & $\begin{array}{l}{ }^{*} \text { Children recruited } \\
\text { in different countries }\end{array}$ & Low \\
\hline $\begin{array}{l}\text { Kinnealey } \\
\text { et al. (2012) }\end{array}$ & Interventional & $\begin{array}{l}\text { Attending } \\
\text { behaviors } \\
\text { (Videotape) } \\
\text { Sensory behaviors } \\
\text { (The Sensory } \\
\text { Profile) } \\
\text { Perceptions } \\
\text { (Journaling) }\end{array}$ & $\begin{array}{l}\operatorname{ASD}(3) \\
\text { Dyspraxia (1) }\end{array}$ & No matching & $13-20$ & $\begin{array}{l}\text { Reduction in } \\
\text { classroom sound as } \\
\text { measured by a } \\
\text { decibel meter after } \\
\text { the installation of } \\
\text { the Owens Corning } \\
\text { Basement Finishing } \\
\text { System }\end{array}$ & $\begin{array}{l}\text { * Findings are not } \\
\text { clear }\end{array}$ & Low \\
\hline $\begin{array}{l}\text { Van Swieten } \\
\text { et al. (2010) }\end{array}$ & $\begin{array}{l}\text { Cross } \\
\text { sectional } \\
\text { control group }\end{array}$ & $\begin{array}{l}\text { Motor and } \\
\text { executive } \\
\text { planning (Grip } \\
\text { selection task with } \\
\text { stimuli on } \\
\text { computer screen) }\end{array}$ & $\begin{array}{l}\text { DCD (27) } \\
\operatorname{ASD}(20) \\
\operatorname{TD}(70)\end{array}$ & $\begin{array}{l}\text { Similar age } \\
\text { DCD was } \\
\text { ensured to } \\
\text { have typical } \\
\text { executive } \\
\text { level } \\
\text { planning, } \\
\text { since ASD has }\end{array}$ & $5-14$ & $\begin{array}{l}\text { DCD: Showed the } \\
\text { predicted bias } \\
\text { towards Minimal } \\
\text { Rotation, and the } \\
\text { proportion of } \\
\text { children with DCD } \\
\text { who showed this } \\
\text { bias was higher than }\end{array}$ & $\begin{array}{l}{ }^{*} \text { Clear difference } \\
\text { between DCD and } \\
\text { ASD groups }\end{array}$ & High \\
\hline
\end{tabular}


Table 3 (Continued)

\begin{tabular}{|c|c|c|c|c|c|c|c|c|}
\hline Study & Design & Variable(s) & Disorders (n) & $\begin{array}{l}\text { Group } \\
\text { matching }\end{array}$ & $\begin{array}{l}\text { Age } \\
\text { (years) }\end{array}$ & $\begin{array}{l}\text { Summary of } \\
\text { findings }\end{array}$ & Observations & Quality \\
\hline $\begin{array}{l}\text { Wisdom et al. } \\
\text { (2007) }\end{array}$ & $\begin{array}{l}\text { Cross } \\
\text { sectional }\end{array}$ & $\begin{array}{l}\text { Intelligence } \\
\text { (Wechsler } \\
\text { Intelligence Scale } \\
\text { for } \\
\text { Children) } \\
\text { Language (Clinical } \\
\text { Evaluation of } \\
\text { Language } \\
\text { Fundamentals) } \\
\text { Motor } \\
\text { coordination } \\
\text { (McCarron } \\
\text { Assessment of } \\
\text { Neuromuscular } \\
\text { Development) } \\
\text { Social ability } \\
\text { (Theory of mind } \\
\text { tasks, Emotion } \\
\text { Recognition } \\
\text { Scales) } \\
\text { Executive } \\
\text { functioning (Go/ } \\
\text { No-Go Task) } \\
\text { Working memory } \\
\text { (Trailmaking/ } \\
\text { Memory Updating } \\
\text { and the Goal } \\
\text { Neglect Task) }\end{array}$ & $\begin{array}{l}\text { ASD (30) } \\
\text { RELD (30) } \\
\operatorname{DCD}(22)\end{array}$ & $\begin{array}{l}\text { problems } \\
\text { with such } \\
\text { tasks }\end{array}$ & $3-13$ & $\begin{array}{l}\text { even the youngest } \\
\text { group of TD } \\
\text { children } \\
\text { ASD: Performed } \\
\text { identically to age- } \\
\text { matched controls } \\
\text { AD and DCD groups } \\
\text { have poorer fine and } \\
\text { gross motor } \\
\text { coordination and } \\
\text { better response } \\
\text { inhibition than the } \\
\text { RELD group } \\
\text { AD and DCD groups } \\
\text { differ in fine and } \\
\text { gross motor } \\
\text { coordination, } \\
\text { emotion } \\
\text { understanding, and } \\
\text { theory of mind } \\
\text { scores (AD always } \\
\text { lower) }\end{array}$ & $\begin{array}{l}\text { Discusses DCD as } \\
\text { part of the autism } \\
\text { diagnosis }\end{array}$ & High \\
\hline $\begin{array}{l}\text { Sumner et al. } \\
\text { (2016) }\end{array}$ & $\begin{array}{l}\text { Cross } \\
\text { sectional } \\
\text { control group }\end{array}$ & $\begin{array}{l}\text { Motor ability } \\
\text { (Early motor } \\
\text { abilities } \\
\text { questionnaire, } \\
\text { Vineland Adaptive } \\
\text { Behavior Scales - } \\
\text { gross and fine } \\
\text { motor scales) } \\
\text { Social functioning } \\
\text { (Benton Test of } \\
\text { Facial Recognition, } \\
\text { Face processing } \\
\text { battery, Vineland } \\
\text { Adaptive Behavior } \\
\text { Scales - } \\
\text { socialization } \\
\text { domain) }\end{array}$ & $\begin{array}{l}\text { ASD (30) } \\
\text { DCD (30) } \\
\text { TD (20) }\end{array}$ & $\begin{array}{l}\text { Similar age } \\
\text { All groups } \\
\text { had IQ }>70 \\
\text { TD group had } \\
\text { did not meet } \\
\text { criteria for } \\
\text { DCD and ASD } \\
\text { on } \\
\text { assessments }\end{array}$ & $7-10$ & $\begin{array}{l}\text { Children with DCD } \\
\text { and ASD were } \\
\text { delayed in reaching } \\
\text { early motor } \\
\text { milestones (DCD } \\
\text { more than ASD) } \\
\text { Children with ASD } \\
\text { and DCD had similar } \\
\text { fine- and gross } \\
\text { motor skills } \\
\text { Children with ASD } \\
\text { and DCD were worse } \\
\text { on face processing } \\
\text { measures compared } \\
\text { to TD children }\end{array}$ & $\begin{array}{l}{ }^{*} \text { Discusses the notion } \\
\text { that DCD may have } \\
\text { problems with social } \\
\text { functioning }\end{array}$ & High \\
\hline $\begin{array}{l}\text { Green et al. } \\
\text { (2015) }\end{array}$ & $\begin{array}{l}\text { Cross } \\
\text { sectional } \\
\text { control group }\end{array}$ & $\begin{array}{l}\text { Self-perception of } \\
\text { movement and } \\
\text { social difficulties } \\
\text { (Harter's Self- } \\
\text { Perception Profile } \\
\text { for Children) } \\
\text { Teacher's } \\
\text { perception of } \\
\text { movement and } \\
\text { social difficulties } \\
\text { (The Teacher } \\
\text { Rating Scale) } \\
\text { Motor skills } \\
\text { (Movement } \\
\text { Assessment } \\
\text { Battery for } \\
\text { Children) } \\
\text { Social } \\
\text { communication }\end{array}$ & $\begin{array}{l}\text { AS (11) } \\
\text { DCD (9) } \\
\text { TD (20) }\end{array}$ & Similar age & $6-10$ & $\begin{array}{l}\text { Children with AS } \\
\text { and DCD rated } \\
\text { themselves as less } \\
\text { competent than the } \\
\text { TD group (especially } \\
\text { in athletic and social } \\
\text { domains, with a } \\
\text { significant } \\
\text { difference between } \\
\text { AS and TD for the } \\
\text { athletic domain) } \\
\text { Teachers } \\
\text { significantly } \\
\text { perceived both the } \\
\text { groups with AS and } \\
\text { DCD as less } \\
\text { competent than the } \\
\text { TD group }\end{array}$ & $\begin{array}{l}\text { * Discuss the lack of } \\
\text { formal diagnosis in } \\
\text { the DCD group and } \\
\text { the unusual good } \\
\text { "ball skills" in this } \\
\text { group as possible } \\
\text { explanation for lower } \\
\text { perception in AS } \\
\text { group }\end{array}$ & High \\
\hline
\end{tabular}


Table 3 (Continued)

\begin{tabular}{|c|c|c|c|c|c|c|c|c|}
\hline Study & Design & Variable(s) & Disorders (n) & $\begin{array}{l}\text { Group } \\
\text { matching }\end{array}$ & $\begin{array}{l}\text { Age } \\
\text { (years) }\end{array}$ & $\begin{array}{l}\text { Summary of } \\
\text { findings }\end{array}$ & Observations & Quality \\
\hline $\begin{array}{l}\text { Caeyenberghs } \\
\text { et al. (2016) }\end{array}$ & $\begin{array}{l}\text { Cross } \\
\text { sectional } \\
\text { control group }\end{array}$ & $\begin{array}{l}\text { (Autistic } \\
\text { Diagnostic } \\
\text { Inventory- } \\
\text { Revised) } \\
\text { Cortical thickness } \\
\text { (MRI) } \\
\text { Motor ability } \\
\text { (Movement } \\
\text { Assessment } \\
\text { Battery for } \\
\text { Children) } \\
\text { Visuomotor } \\
\text { integration } \\
\text { (Beery-Buktenica } \\
\text { Developmental } \\
\text { Test of Visual } \\
\text { Motor Integration) }\end{array}$ & $\begin{array}{l}\text { ASD + DCD } \\
(8) \\
\text { ASD (15) } \\
\text { DCD (11) } \\
\text { TD (19) }\end{array}$ & $\begin{array}{l}\text { Similar age } \\
\text { All groups } \\
\text { had IQ >75 } \\
\text { ADHD was } \\
\text { excluded } \\
\text { from all } \\
\text { groups }\end{array}$ & $8-12$ & $\begin{array}{l}\text { ASD children } \\
\text { showed increased } \\
\text { normalized path } \\
\text { length and higher } \\
\text { values of clustering } \\
\text { coefficient } \\
\text { compared with TD } \\
\text { and DCD } \\
\text { Children with ASD } \\
\text { and DCD exhibited } \\
\text { changes that were } \\
\text { more widespread } \\
\text { than those seen in } \\
\text { children with only } \\
\text { DCD }\end{array}$ & $\begin{array}{l}\text { * Concludes that DCD } \\
\text { and ASD are } \\
\text { neurodevelopmental } \\
\text { disorders with a low } \\
\text { degree of overlap in } \\
\text { abnormalities for } \\
\text { cortical thickness, } \\
\text { and the co- } \\
\text { occurrence of } \\
\text { DCD + ASD was } \\
\text { associated with a } \\
\text { distinct topological } \\
\text { pattern }\end{array}$ & High \\
\hline
\end{tabular}

Note: Acronyms stand for Developmental Coordination Disorder [DCD], Autism Spectrum Disorders [ASD], Specific Language Impairment [SLI], Attention Deficit Hyperactivity Disorder [ADHD], Down Syndrome [DS], Cerebral Palsy [CP], Receptive-Expressive Language Disorder [RELD], and typical development [TD]).

a Previously used by authors.

bias, lacking clear description of participants, assessment of the diagnosis, and a control group. Two studies were identified as interventional, and nine were cross-sectional comparisons among two or more groups. Two studies were qualitative. A wide range of variables were explored across the studies: cognitive ability including intelligence quotient (IQ), executive functioning, attention, and working memory; motor skills including grip selection; perception of motor and social competence; social skills including perceptions of school transitions and social challenges; and "general" abilities, including language, perceived competence, face processing, and cortical connectivity. We grouped the studies into categories (cognitive domain only, motor domain only, social domain only, and multiple domains) for a more cohesive presentation of the results.

\subsection{Cognitive domain only}

Two studies focused specifically on the cognitive domain, testing working memory performance (Alloway et al., 2009) and improvements in IQ following a cognitive intervention (Kozulin et al., 2010). Alloway et al. (2009) compared working memory performance across students with different developmental disorders (SLI, DCD, ADHD, and AS). Working memory was defined as the ability to simultaneously store and process information for a brief period. Children in the DCD, ADHD, and AS groups completed a working memory assessment for verbal and visuospatial aspects of short-term memory and working memory. Memory performance was distinct for each group: children with DCD had depressed performance in all areas, with particularly low scores in visuospatial memory tasks; and children with AS had a selective verbal short-term memory deficit. The authors concluded that memory is a secondary deficit shared across several different developmental disorders, which may be driven by overlap in core deficits.

Kozulin et al. (2010) tested the effectiveness of a cognitive intervention using a multi-center design involving several countries and a broad range of developmental disorders. The intervention was a cognitive enrichment program focusing on perceptual-motor development, decoding emotional expressions, and abstractive/integrative thinking. Scores in three areas of IQ and in nonverbal abilities improved from pre- to post-intervention. However, the impact of the intervention did not vary systematically by disorder.

\subsection{Motor domain only}

Three studies reported data related to the motor domain, including grip selection (Van Swieten et al., 2010), fine- and gross-motor ability and production of gestures (Dewey et al., 2007), and the relationship between motor performance and cortical connectivity (Caeyenberghs et al., 2016).

Van Swieten et al. (2010) used a goal-directed motor planning task to differentiate between motor planning and executive functioning ability in participants with DCD, ASD, and TD. They observed an age-related difference in motor plans motivated by end-state comfort (e.g., making a less comfortable initial grasp to turn an object, so as to end in a comfortable posture) for 
children with and without ASD. These results display a typical developmental trajectory in motor planning. While the ASD group performed identically to the TD group, children with DCD were biased towards selecting the simplest initial movement, which led to uncomfortable end-states after rotation. In addition, the proportion of children with DCD who showed a bias toward this simple initial movement was higher than even the youngest group of TD children. van Swieten and colleagues concluded that motor planning deficits in the DCD group were specifically related to their motor difficulties, rather than to deficits in executive functioning.

Dewey et al. (2007) evaluated motor and gestural performance with a motor proficiency assessment and the production of meaningful gestures to verbal command and through imitation. Their sample included children with ASD, DCD, ADHD, $D C D+A D H D$, and TD. Results indicated that the ASD, DCD, and DCD + ADHD groups had significantly impaired motor coordination; however, only children with ASD showed impairments in gestural performance. In addition, children with ASD made significantly more action and orientation errors during gestural performance in response to verbal command, and significantly more orientation and distortion errors during gestural imitation than children in the DCD, DCD + ADHD, ADHD, and TD groups. The authors concluded that the generalized impairment in gestural performance seen in children with ASD may be influenced by factors other than motor skills.

Caeyenberghs et al. (2016) recently used magnetic resonance imaging to link brain structure to behavioral motor performance and compare cortical thickness in children with DCD, ASD, ASD + DCD, and TD. Both the DCD and ASD + DCD groups performed worse on tests of motor ability and visuomotor integration. Structural architecture of the brain was significantly altered in children with ASD compared to DCD and TD. Children with DCD displayed global network organization that was notably similar to that of TD children, while children with ASD had key differences in their network parameters, namely increased normalized path length and higher values of clustering coefficient. Caeyenberghs and colleagues concluded that the patterns observed in the ASD group reflected an atypical-and as a result, potentially unbalanced and inefficient-network organization. Specifically, high clustering coefficients suggest overconnectivity, which may not be functional. Instead, this pattern of overconnectivity may result in diffuse processing and recruitment of nonspecialized neural mechanisms (Glazebrook \& Wallace, 2015). The increased energetic cost required to transmit signals across a diffuse processing system may in turn decrease efficiency of processing (Bullmore \& Sporns, 2009). With respect to specific network nodes, the DCD group showed increases in clustering coefficient in the lateral orbitofrontal cortex-a part of the expanded limbic system which is especially engaged during response inhibition (Elliott, Dolan, \& Frith, 2000). On the other hand, children with ASD + DCD had more widespread deviations from typical patterns of cortical thickness than those seen in children with only DCD and only ASD, for example, alterations of clustering coefficient in (para)limbic regions, primary areas, and association areas (resulting in more pronounced behavioral and motor issues in this group).

\subsection{Social domain only}

While several studies involved variables linked to social communication (e.g., gesturing, language, face processing), only one study specifically examined children's perceptions of transition from primary to secondary school. Foulder-Hughes and Prior (2014) assessed these perceptions of the school environment in six students with ASD, DCD, and ASD + DCD using interviews and qualitative analysis. Four students had ASD + DCD, one student had DCD, and one student had ASD. Most notably, all students consistently reported worries related to performance in physical education class.

\subsection{Multiple domains}

Sumner et al. (2016) compared motor and face-processing difficulties in children with DCD, ASD, and TD, using a combination of lab assessment and parent reports. Parent reports indicated that children with DCD and ASD could be distinguished from TD on the basis of their early motor development, with a greater distinction between DCD and TD groups than between ASD and TD groups. The DCD and ASD groups were similar in fine- and gross-motor performance during assessment, and notably, half of the group with ASD met the cut-off for motor difficulties on the Movement Assessment Battery for Children - 2nd edition (MABC-2; Henderson, Sugden, \& Barnett, 2007), a criterion-standard test for DCD. In addition, Sumner and colleagues assessed face processing ability, and found that the ASD and DCD groups had similar performance impairments, perhaps driven by visuospatial processing challenges seen in both groups.

Wisdom et al. (2007) created an "ability profile" composed of language, intelligence, social cognition, motor coordination, and executive functioning. They used this profile to assess differences between AD, DCD, and RELD. They observed overlap in deficits across groups, with some distinctions: namely, the AD and DCD groups differed in fine and gross motor skills, emotion understanding, and theory of mind.

Kinnealey et al. (2012) used a quantitative and qualitative mixed-method analysis to explore whether alterations to the sensory environment reduced "non-attending behaviors" in one student with dyspraxia/DCD and three students with ASD. Sound-absorbing walls and halogen lightning were installed in a classroom, and the authors analyzed the frequency of nonattending behaviors captured in videos of class segments. All students demonstrated a decline in non-attending behaviors, and all students self-reported in journals that they noticed the classroom improvements.

Cosper et al. (2009) compared the benefits of an interactive metronome treatment in children with ADHD only, ADHD + PDD, and ADHD + DCD in both sustained attention and motor proficiency. During treatment sessions, children were instructed to practice various combinations of hand and foot movements in time with a PC-based metronome. Children 
made improvements on complex visual choice reaction time and several aspects of motor proficiency. No between-group comparison analyses were performed, so it is unclear whether one group improved more than the others.

Green et al. (2015) evaluated self- and teacher's perception of competence in children with AS, DCD, and typically developing and later correlated with motor and social abilities. Results showed that children with AS and DCD perceived themselves as less competent than the TD group, a view also shared by the teachers.

\section{Discussion}

The goal of the present study was to conduct a SLR gathering all studies that investigated behavioral similarities and differences between groups of individuals diagnosed with ASD, DCD, and ASD + DCD (if included). More specifically, we aimed to identify: (a) what types of behaviors (variables) were compared in ASD and DCD in order to determine similarities or differences between the conditions, and (b) whether any of the studies explored the possibility of co-occurrence between ASD and DCD. Eleven studies met the criteria defined by this study, with seven classified as high quality, one classified as average quality, and three classified as low quality. Based on the results of all studies, particularly the ones of high quality, we explore the fact that while DCD and ASD share some behavioral characteristics, the symptom profiles of each disorder are unique and separable.

\subsection{ASD and DCD: distinct but potentially co-occurring disorders}

The eleven studies reviewed reported important differences between individuals with ASD and DCD, suggesting that they are indeed separable, but potentially co-occurring, diagnoses. Most of the high quality studies suggested that individuals with ASD, DCD, and ASD + DCD have symptoms spanning several domains. Notable distinctions between ASD and DCD were found in working memory ability, gestural performance, severity of motor challenges, grip selection, and cortical thickness. For example, a clear distinction was found between the two disorders for working memory ability (Alloway et al., 2009), such that children with DCD had noticeable visuospatial working memory deficits, performing worse than those with AS, while children with AS only had poor performance in verbal short-term memory. However, as Alloway et al. (2009) suggest, known visual and motor system differences in ASD and DCD may mediate or moderate the relationship between disorder and working memory task performance. Since evidence suggests that AS is indistinct from the rest of the autism spectrum (Miller \& Ozonoff, 2000), new studies are needed to determine whether the same working memory profile is present a broader range of symptom severity.

When comparing gestural performance, a clear distinction also emerged: while the ASD, DCD, and DCD + ADHD groups were all significantly impaired on motor coordination skills, only children with ASD showed an impairment in gestural performance (Dewey et al., 2007). These findings suggest that gestural impairments in ASD are not solely attributable to deficits in motor coordination skills. In grip selection, children with DCD showed the predicted bias towards minimal rotation, while children with ASD performed identically to age-matched controls (Van Swieten et al., 2010).

The most recent study, and the only one that directly assessed brain structure, found clear differences in neural architecture between ASD, DCD, and ASD + DCD (Caeyenberghs et al., 2016). This result underscores the idea that ASD and DCD are separable, but can be co-occurring. However, behavioral distinctions may not be easily identified, given that children with ASD and DCD may have similar motor and face-processing challenges (Sumner et al., 2016). Motor impairments are common in ASD, but the body of available evidence suggests that for some, they may be severe enough to warrant a diagnosis of co-occurring DCD, while for others, they may not. Some evidence also suggests that children with DCD have social challenges, but these are thought to stem from difficulty interacting with and performing skills at the same level as TD children because of their motor symptoms, rather than reflecting a fundamental difference in social communication ability (Chen \& Cohn, 2009; Dewey et al., 2002). One limitation of some studies with DCD is the fact that children with DCD are typically not tested for ASD, or ASD might not be fully excluded in groups of DCD. The issue of potential co-occurrence is not limited to ASD and DCD, but rather, may extend to other developmental disorders as suggested by the DAMP hypothesis (Gillberg \& Kadejo, 2003). This theoretical perspective posits that co-occurrence between DCD, ADHD, and ASD can be described in terms of symptom overlap, namely, deficits in attention, motor control, and perception. The findings of this SLR add to the body of literature that supports the DSM- 5 method of describing DCD and ASD as unique and distinct diagnostic conditions with the possibility of co-occurrence.

As Wisdom et al. (2007) and others have noted, processes underlying motor skill deficits may play a key role in ASD. Indeed, both behavioral and imaging data support this conclusion (Ming et al., 2007; Ozonoff et al., 2008; Vernazza-Martin et al., 2005), and so it is essential that studies involving ASD and DCD include thorough assessment of motor skills, especially when these are likely to affect the outcome of the experiment. However, it is important to note that children with ASD may require adjustments to traditional motor assessments, in order to overcome communication barriers and facilitate optimal performance. For example, Breslin and Rudisill (2011) elicited more accurate gross motor scores for children with ASD on the Test of Gross Motor Development by using a picture task card protocol, which eliminated receptive and expressive language demands often associated with motor assessments. 


\subsection{Potential similarities in $A S D$ and $D C D$}

Interestingly, Wisdom et al. (2007) found both similarities and differences for DCD and AD, such that the DCD group had higher theory of mind, emotion recognition, and fine and gross motor coordination than the AD group, but similar response inhibition abilities. Wisdom and colleagues noted that when stratified by symptom severity, children with AD who were classified as "more able" did not differ on any measures from children with DCD, unlike children who were classified as "less able". Given this result, the authors questioned whether AD and DCD differ more in the possible range of symptom severity than in any specific behavioral domain.

The recent study by Sumner et al. (2016) also demonstrated several overlapping characteristics in face processing, expression, speech sound, and gaze for groups of ASD and DCD, suggesting that children with DCD may have problems processing social information. However, the DCD group scored at an intermediate level (between TD and ASD) in two other measures of socialization, which led the authors to conclude that socialization in the DCD group may not be as marked as those seen in the ASD group.

The clearest similarity between DCD and ASD in the studies we reviewed was a lack of significant response to cognitive intervention. With respect to intervention studies, no differences in improvement were observed between ASD and DCD groups in attention (Cosper et al., 2009; Kinnealey et al., 2012) or IQ (Kozulin et al., 2010). It is possible that the capacity to train and improve in several domains, especially cognition, is similar for these conditions. In addition, no differences were found in a qualitative study investigating the transition from primary to secondary school, possibly because the main variables of interest related to their motor difficulties.

\subsection{Challenges to accurate diagnostic classification}

There is still a striking lack of consensus in the field about whether DCD and ASD are distinct and mutually-exclusive disorders with some shared motor features, or whether some individuals with ASD have DCD while others do not. As new evidence emerges, researchers and clinicians will be better-equipped to make recommendations regarding diagnosis and intervention. Additionally, clinicians recommending a DCD diagnosis must carefully evaluate DSM-5 criterion D-whether motor skill deficits are better explained by intellectual disability, visual impairment, or a neurological condition-to determine whether there is a potential for co-occurrence with ASD.

Several key issues may arise when attempting to diagnose both ASD and DCD in the same child. In a child with ASD, a diagnosis of ASD will likely occur first, given that it can be reliably diagnosed as early as 24 months (Lord et al., 2006). Therefore, motor symptoms 1) may not be comprehensively assessed, 2) thought to be more than secondary consequences of ASD or 3) may not be prioritized in assessment given that motor skills change as a function of development and/or maturation. Conversely, DCD is typically only diagnosed after age 6 (Van Waelvelde et al., 2010), although an exception may be made if a child between 3 and 5 years shows a marked motor impairment (Blank et al., 2012). Therefore, for children with ASD diagnosed before school age, the most likely question will be whether to add DCD to an existing ASD diagnosis. However, the average age of ASD diagnosis remains around 5 years (CDC, 2016), with many children only receiving a full assessment and diagnosis when they reach the school system. In these instances, it is less straightforward which diagnosis a child should carry, and how to address comorbidities.

The question of whether children can be reliably diagnosed (or perhaps screened for) DCD earlier than age 6 is also important. Fundamental motor skills (e.g., running, jumping, hopping, throwing, etc.) are building blocks for more complex motor behaviors (e.g., gesturing) and long-term engagement in physical activity (Cairney \& King-Dowling, 2016). Given the demonstrated efficacy of early interventions focused on motor development it is critically important to identify at-risk and affected children as early as possible (Blauw-Hospers \& Hadders-Algra, 2005). At present, the most common diagnostic tools for DCD are the Developmental Coordination Disorder Questionnaire (DCD-Q; Wilson et al., 2009) and MABC-2 (Henderson et al., 2007). However, given the individual variability in the slope of motor developmental trajectories, it remains difficult to reliably identify DCD in very young children.

Another important aspect to be considered is the distinction between dyspraxia and DCD. DCD is a fairly recent term, introduced in DSM-III (APA, 2013), though the phenomenology was noted as early as 1925 and established in the literature in the 1960s (for review, see Kirby \& Sugden, 2007). In 1994, the international research community determined that the term DCD should replace dyspraxia in both research and practice (Polatajko \& Cantin, 2006). Nonetheless, some studies continue to use the term dyspraxia to describe a range of motor impairments in ASD (e.g., Abelenda et al., 2015). It is important to clarify the definition of dyspraxia in future assessments. While dyspraxia and DCD should be used interchangeably as a specific diagnostic classification, some researchers and clinicians refer to imitation deficits seen in ASD (often measured by observation of gestures) and other motor symptoms as dyspraxia, without reference to a specific co-occurrence. A DCD diagnosis involves much more than observation of gestures or specific motor behaviors in a research study, and should include a thorough evaluation of motor skills and the impact that motor difficulties have on activities of daily living.

\subsection{Limitations}

The most significant limitation of the present review is the sample size. Since so few studies have directly compared ASD and DCD, our conclusions are preliminary and warrant further exploration as the available body of literature increases. In 
addition, differences in study designs (comparative, interventional) compromised our ability to make significant cross-study comparisons. The number of co-occurrences present in the studies also limited our ability to generalize results to all individuals diagnosed with DCD, ASD, or both. In general, numerous complex confounding factors create unique challenges for studies investigating neurodevelopmental disorders and potential co-occurrences. Apart from controlling for cognitive ability, broadly defined as IQ $\geq 70$, few studies directly address specific domains in which individuals may differ (see Table 3), leaving questions about potential confounds that limit the ability to compare findings between and within groups. Finally, though our conclusions are based on the studies that met 'high quality' criteria, it is notable that three studies included in this review were classified as 'poor quality'. Despite these limitations, our findings offer the benefit of exposing gaps in the literature and drawing attention to important questions about the specific nature of overlap between ASD and DCD.

\section{Conclusions}

Overall, the high quality studies selected for this review reported more differences than similarities between the ASD and DCD in several behavioral domains, with notable overlap in symptoms for some individuals with ASD + DCD. Symptom overlap between the two conditions was particularly notable in the domain of motor skills. These results suggest that ASD and DCD are, as currently classified in DSM-5, separable but potentially co-occurring disorders. Perhaps the greatest challenge to understanding the relationship between DCD and ASD is a dearth of studies with large, well-defined samples. Future studies should include consideration of co-occurrence between disorders, age and developmental trajectory, task demands, and the sensitivity of diagnostic and assessment tools used. Urgent attention is needed to determine the breadth and depth of shared symptoms between ASD and DCD, and how best to classify persons for the purpose of intervention. The extant literature suggests that these are dissociable disorders. However, it is still unknown whether the motor features observed in both ASD and DCD vary among individuals along a spectrum of severity and functional impact, or whether their severity and functional impact can be used diagnostically to distinguish between ASD, DCD, and ASD + DCD. As the field awaits further studies that contribute to our understanding of the nuanced differences and similarities between these disorders, we recommend systematic and thorough evaluation of motor skills in individuals with ASD. This will aid clinicians in making important choices about intervention, informed by the distinction between individuals with co-occurring ASD + DCD and individuals with ASD who display some motor differences but do not meet criteria for DCD.

\section{Funding acknowledgments}

Research reported in this publication was supported in part by the National Center for Advancing Translational Science of the National Institutes of Health under the Center for Translational Medicine [KL2TR001103]. The content is solely the responsibility of the authors, and does not necessarily represent the official views of the NIH.

\section{References}

American Psychiatric Association (2013). Diagnostic and statistical manual of mental disorders, (5th ed.) Washington, DC: Author.

Abelenda, J., Mailloux, Z., \& Roley, S. S. (2015). Dyspraxia in autism spectrum disorders: Evidence and implications. Sensory Integration Special Interest Section Quarterly, 38(3), 1-4.

Alloway, T. P., Rajendran, G., \& Archibald, L. M. D. (2009). Working memory in children with developmental disorders. Journal of Learning Disabilities, 42(4), 372-382. http://dx.doi.org/10.1177/0022219409335214.

Blank, R., Smits-Engelsman, B., Polatajko, H., \& Wilson, P. (2012). European Academy for Childhood Disability (EACD): Recommendations on the definition, diagnosis and intervention of developmental coordination disorder (long version). Developmental Medicine E' Child Neurology, 54, 54-93. http://dx.doi. org/10.1111/j.1469-8749.2011.04171.x.

Blauw-Hospers, C. H., \& Hadders-Algra, M. (2005). A systematic review of the effects of early intervention on motor development. Developmental Medicine $\mathcal{E}$ Child Neurology, 47(6), 421-432. http://dx.doi.org/10.1111/j.1469-8749.2005.tb01165.x.

Breslin, C. M., \& Rudisill, M. E. (2011). The effect of visual supports on performance of the TGMD-2 for children with Autism Spectrum Disorder. Adapted Physical Activity Quarterly, 28, 342-353.

Bullmore, E., \& Sporns, O. (2009). Complex brain networks: A graph theoretical analysis of structural and functional systems. Nature Reviews Neuroscience, 10, 186-198. http://dx.doi.org/10.1038/nrn2575.

Bundy, A. C., Lane, S. J., \& Murray, E. A. (2002). Sensory integration: Theory and practice, (2nd ed.) Philadelphia, PA: F. A. Davis.

Caeyenberghs, K., Taymans, T., Wilson, P. H., Vanderstraeten, G., Hosseini, H., \& van Waelvelde, H. (2016). Neural signature of developmental coordination disorder in the structural connectome independent of comorbid autism. Developmental Science, 19(4), 599-612. http://dx.doi.org/10.1111/desc.12424.

Cairney, J., \& King-Dowling, S. (2016). Developmental Coordination Disorder. In J. L. Matson (Ed.), Comorbid conditions among children with autism spectrum disorders (pp. 303-322). New York, NY: Springer.

Christensen, D. L., Baio, J., Braun, K. V., Bilder, D., Charles, J., Constantino, J. N., ... Yeargin-Allsopp, M. (2016). Prevalence and characteristics of autism spectrum disorder among children aged 8 years - autism and developmental disabilities monitoring network, 11 sites, United States, 2012 . MMWR Surveillance Summaries, 65(SS-3), 1-23. http://dx.doi.org/10.15585/mmwr.ss6503a1.

Cosper, S. M., Lee, G. P., Peters, S. B., \& Bishop, E. (2009). Interactive Metronome training in children with attention deficit and developmental coordination disorders. International Journal of Rehabilitation Research, 32(4), 331-336. http://dx.doi.org/10.1097/mrr.0b013e328325a8cf.

Dewey, D., Kaplan, B. J., Crawford, S. G., \& Wilson, B. N. (2002). Developmental coordination disorder: Associated problems in attention, learning, and psychosocial adjustment. Human Movement Science, 21(5-6), 905-918. http://dx.doi.org/10.1016/S0167-9457(02)00163-X.

Dewey, D., Cantell, M., \& Crawford, S. G. (2007). Motor and gestural performance in children with autism spectrum disorders, developmental coordination disorder, and or attention deficit hyperactivity disorder. Journal of the International Neuropsychological Society, 13, 246-256. http://dx.doi.org/10.1017/ s1355617707070270.

Donnellan, A. M., Hill, D. A., \& Leary, M. R. (2013). Rethinking autism: Implications of sensory and movement differences for understanding and support. Frontiers in Integrative Neuroscience, 6. http://dx.doi.org/10.3389/fnint.2012.00124. 
Downey, R., \& Rapport, M. K. (2012). Motor activity in children with autism: A review of current literature. Pediatric Physical Therapy, 24, 2-10. http://dx.doi. org/10.1097/pep.0b013e31823db95f.

Dziuk, M. A., Gidley Larson, J. C., Apostu, A., Mahone, E. M., Denckla, M. B., \& Mostofsky, S. H. (2007). Dyspraxia in autism: Association with motor, social, and communicative deficits. Developmental Medicine and Child Neurology, 49(10), 734-739. http://dx.doi.org/10.1111/j.1469-8749.2007.00734.x.

Elliott, R., Dolan, R. J., \& Frith, C. D. (2000). Dissociable functions in the medial and lateral orbitofrontal cortex: Evidence from human neuroimaging studies. Cerebral Cortex, 10(3), 308-317. http://dx.doi.org/10.1093/cercor/10.3.308.

Foulder-Hughes, L., \& Prior, C. (2014). Supporting pupils with DCD and ASD with the transition to secondary school. Research in Education, 92, 79-92. http:// dx.doi.org/10.7227/rie.0011.

Fournier, K. A., Hass, C. J., Naik, S. K., Lodha, N., \& Cauraugh, J. H. (2010). Motor coordination in autism spectrum disorders: A synthesis and meta-analysis. Journal of Autism and Developmental Disorders, 40, 1227-1240. http://dx.doi.org/10.1007/s10803-010-0981-3.

Gibbs, J., Appleton, J., \& Appleton, R. (2007). Dyspraxia or developmental coordination disorder? Unravelling the enigma. Archives of Disease in Childhood, 92 534-539. http://dx.doi.org/10.1136/adc.2005.088054.

Glazebrook, J. F., \& Wallace, R. (2015). Pathologies in functional connectivity, feedback control and robustness: A global workspace perspective on autism spectrum disorders. Cognitive Processing, 16(1), 1-16. http://dx.doi.org/10.1007/s10339-014-0636-y.

Green, D., Baird, G., Barnett, A. L., Henderson, L., Huber, J., \& Henderson, S. E. (2002). The severity and nature of motor impairment in Asperger's syndrome: A comparison with specific developmental disorder of motor function. Journal of Child Psychology and Psychiatry, 43(5), 655-668. http://dx.doi.org/ $10.1111 / 1469-7610.00054$.

Green, D., Arscott, C., Barnett, A. L., Henderson, L., Henderson, S. E., Huber, J., et al. (2015). Impairment of movement and social difficulties in children with Autism Spectrum Disorder (Asperger Syndrome) and Developmental Coordination Disorder - how are they perceived by the children and their teachers? In A. L. Barnett, \& D. A. Sugden (Eds.), Moving, Developing and Learning. A Festschrift in celebration of the career of Sheila E. Henderson, Oxford Brookes University. ISBN: 978-1-873640-87-6.

Henderson, S. E., Sugden, D. A., \& Barnett, A. L. (2007). Movement assessment battery for children, (2nd ed.) San Francisco, CA: Pearson.

Jongmans, M. J., Smits-Engelsman, B. C. M., \& Schoemaker, M. M. (2003). Consequences of comorbidity of developmental coordination disorders and learning disabilities for severity and pattern of perceptual-Motor dysfunction. Journal of Learning Disabilities, 36(6), 528-537. http://dx.doi.org/10.1177/ 00222194030360060401.

Kanner, L. (1943). Autistic disturbances of affective contact. Nervous Child, 2, 217-250.

Kaplan, B. J., Dewey, D. B., Crawford, S. G., \& Wilson, B. N. (2001). The term comorbidity is of questionable value in reference to developmental disorders: Data and theory. Journal of Learning Disabilities, 34(6), 555-565. http://dx.doi.org/10.1177/002221940103400608.

Kinnealey, M., Pfeiffer, B., Miller, J., Roan, C., Schoener, R., \& Ellner, M. L. (2012). Effect of classroom modification on attention and engagement of students with autism or dyspraxia. The American Journal of Occupational Therapy, 66(5), 511-519. http://dx.doi.org/10.5014/ajot.2012.004010.

Kirby, A., \& Sugden, D. (2007). Children with developmental coordination disorders. Journal of the Royal Society of Medicine, 100(4), 182-186. http://dx.doi. org/10.1258/jrsm.100.4.182.

Kozulin, A., Lebeer, J., Madella-Noja, A., Gonzalez, F., Jeffrey, I., et al. (2010). Cognitive modifiability of children with developmental disabilities: A multicentre study using Feuerstein's Instrumental Enrichment-Basic program. Research in Developmental Disabilities, 31, 551-559. http://dx.doi.org/10.1016/j. ridd.2009.12.001.

Leonard, H. C., \& Hill, E. L. (2014). Review: The impact of motor development only typical and atypical social cognition and language: A systematic review. Child and Adolescent Mental Health, 19(3), 163-170. http://dx.doi.org/10.1111/camh.12055.

Lord, C., Risi, S., DiLavore, P. S., Shulman, C., Thurm, A., \& Pickles, A. (2006). Autism from 2 to 9 years of age. Archives of General Psychiatry, 63(6), 694-701. http://dx.doi.org/10.1001/archpsyc.63.6.694.

Miller, J., \& Ozonoff, S. (2000). The external validity of Asperger Disorder: Lack of evidence from the domain of neuropsychology. Journal of Abnormal Psychology, 109(2), 227-238.

Ming, X., Brimacombe, M., \& Wagner, G. C. (2007). Prevalence of motor impairment in autism spectrum disorders. Brain Development, 29(9), 565-570. http:// dx.doi.org/10.1016/j.braindev.2007.03.002.

Missiuna, M., \& Magalhães, L. (2015). Prospecting in the field of developmental coordination disorder. Physical E' Occupational Therapy in Pediatrics, 35(2), 93-96. http://dx.doi.org/10.3109/01942638.2015.1013758.

Moher, D., Liberati, A., Tetzlaff, J., \& Altman, D. G. (2009). The PRISMA group preferred reporting items for systematic reviews and meta-Analyses: The PRISMA statement. PLoS Medicine, 6(7). http://dx.doi.org/10.1371/journal.pmed.1000097.

Ozonoff, S., Young, G. S., Goldring, S., Greiss-Hess, L., Herrera, A. M., Steele, J., . . . Rogers, S. J. (2008). Gross motor development, movement abnormalities, and early identification of autism. Journal of Autism and Developmental Disorders, 38, 644-656. http://dx.doi.org/10.1007/s10803-007-0430-0.

Polatajko, H. J., \& Cantin, N. (2006). Developmental Coordination Disorder(Dyspraxia): An overview of the state of the art. Seminars in Pediatric Neurology, 12 $250-258$.

Simonoff, E., Pickles, A., Charman, T., Chandler, S., Loucas, T., \& Baird, G. (2008). Psychiatric disorders in children with autism spectrum disorders: Prevalence comorbidity, and associated factors in a population-derived sample. Journal of the American Academy of Child E Adolescent Psychiatry, 47(8), 921-929. http://dx.doi.org/10.1097/CHI.0b013e318179964f.

Sumner, E., Leonard, H. C., \& Hill, E. L. (2016). Overlapping phenotypes in autism spectrum disorder and developmental coordination disorder: A crosssyndrome comparison of motor and social skills. Journal of Autism and Developmental Disorders, 46, 2609-2620. http://dx.doi.org/10.1007/s10803-0162794-5.

Van Swieten, L. M., Williams, J. H. G., Plumb, M. S., van Bergen, E., Wilson, A. D., Kent, S. W., et al. (2010). A test of motor (not executive) planning in Developmental Coordination Disorder and Autism. Journal of Experimental Psychology: Human Perception and Performance, 36(2), 493-499. http://dx.doi. org/10.1037/a0017177.

Van Waelvelde, H., Oostra, A., Dewitte, G., Van den Broeck, C., \& Jongmans, M. J. (2010). Stability of motor problems in young children with or at risk of autism spectrum disorders, ADHD, and or developmental coordination disorder. Developmental Medicine E' Child Neurology, 52, e174-e178. http://dx.doi.org/ $10.1111 / j .1469-8749.2009 .03606 . x$.

Vernazza-Martin, S., Martin, N., Lepellec-Muller, A., Rufo, M., Massion, J., \& Assaiante, C. (2005). Goal directed locomotion and balance control in autistic children. Journal of Autism and Developmental Disorders, 35(1), 91-102. http://dx.doi.org/10.1007/s10803-004-1037-3.

Whyatt, C., \& Craig, C. (2013). Sensory-motor problems in autism. Frontiers in Integrative Neuroscience, 51(7). http://dx.doi.org/10.3389/fnint.2013.00051.

Wilson, B. N., Crawford, S. G., Green, D., Roberts, G., Aylott, A., \& Kaplan, B. J. (2009). Psychometric properties of the revised Developmental Coordination Disorder questionnaire. Journal of Physical and Occupational Therapy in Pediatrics, 29(2), 182-202. http://dx.doi.org/10.1080/01942630902784761.

Wisdom, S. N., Dyck, M. J., Piek, J. P., Hay, D., \& Hallmayer, J. (2007). Can autism, language and coordination disorders be differentiated based on ability profiles? European Child E Adolescent Psychiatry, 16, 178-186. http://dx.doi.org/10.1007/s00787-006-0586-8. 